\title{
Medication therapy: adherence, knowledge and difficulties of elderly people from bipolar disorder
}

\author{
Ligiane Paula da Cruz ${ }^{1}$ \\ Patrícia Monforte Miranda ${ }^{2}$ \\ Kelly Graziani Giacchero Vedana ${ }^{3}$ \\ Adriana Inocenti Miasso ${ }^{4}$
}

This study aimed to verify the adherence, knowledge and the difficulties of elderly patients with Bipolar Affective Disorder (BAD) in relation to the prescribed pharmacological therapy for the control of this disorder. The study included 17 elderly patients with BAD treated at a Mental Health Center. Semi-structured interviews were conducted and scales were applied. The data were analyzed using a quali-quantitative approach. A low level of adherence to the pharmacological treatment and a deficit in knowledge in relation to the medication were identified, especially regarding the dose and frequency of administration. Among the difficulties inherent to the pharmacotherapy, the obligation of polypharmacotherapy, the desire to quit the pharmacological treatment, limitations in the self-administration of the medication, collateral effects, and doubts about the need for the medication were related. Investment is needed in educational activities and in the promotion of adherence that address the difficulties experienced by elderly people with $B A D$ in the following of the pharmacotherapy in order to ensure safety in the medication therapy.

Descriptors: Bipolar Disorder; Medication Adherence; Aged.

\footnotetext{
${ }^{1}$ Nursing undergraduate student, Escola de Enfermagem de Ribeirão Preto, Universidade de São Paulo, WHO Collaborating Centre for Nursing Research Development, SP, Brazil. E-mail: ligiane_paula@hotmail.com.

2 RN. E-mail: patricia.miranda@usp.br.

${ }^{3}$ RN, Doctoral Student, Escola de Enfermagem de Ribeirão Preto, Universidade de São Paulo, WHO Collaborating Centre for Nursing Research Development, SP, Brazil. E-mail: kellygiacchero@yahoo.com.br.

${ }^{4}$ RN, Ph.D. in Nursing, Professor, Escola de Enfermagem de Ribeirão Preto, Universidade de São Paulo, WHO Collaborating Centre for Nursing Research Development, SP, Brazil. E-mail: amiasso@eerp.usp.br.
}

Corresponding Author:

Adriana Inocenti Miasso

Universidade de São Paulo. Escola de Enfermagem de Ribeirão Preto

Departamento de Enfermagem Psiquiátrica e Ciências Humanas

Av. dos Bandeirantes, 3900

Bairro: Monte Alegre

CEP: 14040-902, Ribeirão Preto, SP, Brasil

E-mail: amiasso@eerp.usp.br 


\title{
Terapêutica medicamentosa: adesão, conhecimento e dificuldades de idosos com transtorno bipolar
}

Este estudo teve como objetivo verificar a adesão, o conhecimento e as dificuldades de idosos com transtorno afetivo bipolar (TAB), em relação à terapêutica medicamentosa, prescrita para controle do referido transtorno. Participaram do estudo 17 idosos com TAB atendidos em um núcleo de saúde mental. Foram realizadas entrevista semiestruturada e aplicação de escalas. Os dados foram analisados com abordagem quali-quantitativa. Identificou-se baixo grau de adesão ao tratamento farmacológico e déficit no conhecimento sobre os medicamentos, especialmente sobre as doses e frequência de administração. Entre as dificuldades inerentes à farmacoterapia relataram-se: a obrigatoriedade da polifarmacoterapia, o desejo de encerrar o tratamento farmacológico, limitações na autoadministração dos fármacos, efeitos colaterais e dúvidas sobre a necessidade dos medicamentos. São necessários investimentos em ações educativas e de promoção da adesão que contemplem as dificuldades vivenciadas pelos idosos com TAB, no seguimento da farmacoterapia, para garantia de segurança na terapêutica medicamentosa.

Descritores: Transtorno Bipolar; Adesão à Medicação; Idoso.

\section{Terapéutica medicamentosa: adhesión, conocimiento y dificultades de personas ancianas portadoras de trastorno bipolar}

\begin{abstract}
Este estudio tuvo como objetivo verificar la adhesión, el conocimiento y las dificultades de ancianos con Trastorno Afectivo Bipolar (TAB) en relación a la terapéutica medicamentosa prescrita para control del referido trastorno. Participaron del estudio 17 ancianos con TAB atendidos en un Núcleo de Salud Mental. Fueron realizadas entrevistas semiestructuradas y aplicación de escalas. Los datos fueron analizados con abordaje cualitativo-cuantitativo. Se identificó bajo grado de adhesión al tratamiento farmacológico y déficit en el conocimiento sobre los medicamentos, especialmente sobre las dosis y frecuencia de administración. Entre las dificultades inherentes a la fármacoterapia fueron relatadas la obligatoriedad de la polifármacoterapia, el deseo de terminar el tratamiento farmacológico, las limitaciones en la auto-administración de los fármacos, los efectos colaterales y las dudas sobre la necesidad de los medicamentos. Se concluye que son necesarias inversiones en acciones educativas y de promoción de la adhesión que contemplen las dificultades experimentadas por los ancianos con TAB en el seguimiento de la fármacoterapia para garantizar la seguridad en la terapéutica medicamentosa.
\end{abstract}

Descriptores: Trastorno Bipolar; Cumplimiento de la Medicación; Anciano.

\section{Introduction}

Brazil is going through an accelerated aging process of the Brazilian society. In 2006, there were approximately 19 million individuals over 60 years of age ${ }^{(1)}$. A consequence of the aging of the population is an increase in the prevalence of chronic conditions and a high consumption of medication ${ }^{(2-3)}$. Bipolar Affective Disorder (BAD) in the elderly is a growing public health problem $^{(4)}$. However, there is a lack of epidemiological studies on the disorder in this age group ${ }^{(5)}$. It is known that in the United States, the prevalence rates of BAD in the elderly vary between $0.1 \%$ and $0.4 \%$. However, this disorder affects around $10 \%$ to $25 \%$ of all elderly patients with mood disorders and is responsible for $5 \%$ of the hospitalizations of elderly due to psychiatric causes in the country ${ }^{(6)}$. In Brazil, there is no accurate information on the incidence and prevalence of BAD in the elderly. However, the diagnosis of BAD in the elderly is highlighted as a cause of psychiatric hospitalizations 
in this group ${ }^{(5)}$. Drug treatment is essential for the control of BAD in all its stages and in all ages(6). However, the success of pharmacotherapy is conditional on the adherence to medication treatment and there are several factors that act as barriers to the adherence of the person with BAD to the medication. Among these barriers, may be the lack of knowledge regarding the prescribed medication ${ }^{(7)}$.

Research conducted in 2007 in the same service in which the present study was performed investigated the adherence to treatment and the satisfaction with the healthcare team and pharmacotherapy in adults with BAD. The study found that although most patients claimed satisfaction with the effectiveness of the medication and with the information received in the health service, only $28.5 \%$ of the patients adhered to the pharmacological treatment ${ }^{(8)}$. However, there are no studies that evaluate the medication adherence and the knowledge regarding the medication of the contingent of elderly people with BAD. It is a fact that elderly patients with BAD often have specific needs related to treatment compared with young individuals. These requirements are due to factors typical of old age: physical comorbidities (especially chronic diseases) social isolation, cognitive alterations, limitations in performing activities of daily living, polypharmacy, and age-related variations in the response to therapy, among others ${ }^{(2,6)}$. It can be verified, in the literature, that the specifics of the management of the pharmacological treatment of BAD geriatrics have been little studied in comparison with management in the young population. An advance in the development of scientific knowledge regarding $B A D$ geriatrics and their treatment could provide an improvement in the care to this $\operatorname{group}^{(4-6,9)}$. The entire context described points to the importance of research on the adherence to pharmacotherapy, as well as the knowledge and difficulties of elderly patients with BAD related to prescription medication, with the aim of providing subsidies for the optimization of the treatment offered to this clientele.

\section{Aims}

This study aimed to determine the degree of adherence, the level of knowledge and the difficulties of elderly people with BAD related to the following of the prescribed pharmacological therapy.

\section{Methodology}

This is a cross-sectional, descriptive, quailquantitative study. It was held in the domiciles of elderly people with BAD treated at a mental health center (MHC), of a municipality in the interior of São Paulo State, which is part of the Brazilian National Health System (SUS). The project was developed after its approval by the Research Ethics Committee of the institution (Protocol No.269/CEP-CSE-FMRP-USP). All patients aged 60 or older, diagnosed with BAD, with continuous use of medication for treatment of this disorder and who had consultations scheduled with the physicians of the MHC within the period of three months after the start of data collection, were selected for the study. Further inclusion criteria adopted were: to be able to communicate verbally, to agree to participate in the study and to sign the terms of informed consent. The Mini Mental State Examination (Mini-Mental)(10) was applied, using, according to this examination, a score of less than 24 for educated subjects and scores below 18 for the illiterate as criteria for exclusion from the study ${ }^{(11)}$.

For the data collection a semi-structured interview was used, guided by a script prepared by the authors of the study, which consisted of data on the characterization of the subjects, questions related to adherence and to the knowledge of the elderly about the instituted pharmacotherapy, and data referring to the difficulties of the participants in relation to following the pharmacological treatment. The data were analyzed using a quali-quantitative approach. The degree of adherence was defined by applying the Morisky-Green test ${ }^{(12)}$. This test identifies the degree of patient adherence and discriminates as to whether the possible non-adherence is due to intentional behavior (questions: "When you feel well, do you ever stop taking your medication?" and "when you don't feel well, even with the medication, do you stop taking it sometimes?") or unintentional behavior (questions: "have you ever forgotten to take your medicine?" and "are you sometimes careless about the time to take your medicine?"). The test was validated in other studies and has been translated and applied in Brazil(13-15). The responses were assigned a value of 0 (zero) or 1 , with the value 1 given for each positive response in which the admitted frequency was of once per month or less, and the value 0 (zero) for other possibilities of frequency. The criterion adopted to classify the degree of adherence was: "adherent" the patients who obtained four points in Morisky-Green test $^{(12)}$ and "non-adherent" those who obtained 0 to 3 points.

To categorize the degree of knowledge of the patients regarding prescribed medication, a scale was adopted already employed in previous studies(16-17). In 
this scale, the degree of knowledge can be categorized from 0 to $100 \%$ in five intervals representing the following classes: "without knowledge" (0\%) "very little knowledge" $(0 \%+25 \%)$, "little knowledge" $(25 \%$ $\dashv 50 \%)$; "average knowledge" (50\% $\nmid 75 \%)$ and "good knowledge" (75\% $+100 \%)$. This scale was used to categorize the degree of patient knowledge regarding the following aspects of the medication: name, dose and frequency of use. The answer to each question was classified as right or wrong, considering each medication prescribed for the patient. The answer "do not know" was classified as wrong. Thus, when there were 10 medications prescribed for a patient, if the patient was able to correctly report the names of four of them, the degree of knowledge of the patient would be $40 \%$ and they would be included in the category "little knowledge" in relation to the names of the medication. Proceeding in this way for the other variables related to the medication.

The data related to the characterization of study participants and to their knowledge about the pharmacological therapy were entered into a structured database in spreadsheet format, using the Excel program and subsequently transported to the Statistical Package for the Social Sciences (SPSS version11.5). For analysis of the data concerning the difficulties of the patients in following the pharmacotherapy, a qualitative approach was used, based on the steps proposed by Minayo(18): sorting of the collected data, classification of the data (development of the central empirical categories) and the final analysis (articulation of the empirical data with the literature).

\section{Results}

\section{Categorization of the study subjects}

Within three months of the start of the study, 17 elderly people with BAD who fulfilled the study inclusion criteria had scheduled medical consultations in the mental health center. Of these 17 patients interviewed, it was verified that the majority were female $(76.47 \%)$, married $(52.94 \%)$, retired due to the disorder $(70.58 \%)$ and had incomplete elementary education (58.82\%). Regarding the medications used by the study subjects for the control of psychiatric symptoms, it was found that 15 patients $(88.24 \%$ ) were using mood stabilizers and that antipsychotics were prescribed for seven (41.18\%) interviewees. It is also noteworthy that five $(29.41 \%)$ were taking benzodiazepines and three (17.65\%) individuals were using antidepressants.

\section{Behavior related to adherence to the pharmacological treatment}

Adherence to the pharmacological treatment was assessed using the Morisky-Green test ${ }^{(12)}$ which allows the evaluation of whether the possible nonadherence is due to intentional behavior (stop taking the medication because they feel well or feel bad) or unintentional (forgetfulness and carelessness regarding the time of medication). Among those investigated, only two patients $(11.76 \%)$ were identified that adhered to the prescribed pharmacological treatment. Of the total interviewees, 11 (64.72\%) were non-adherent through unintentional behavior, while two $(11.76 \%)$ were nonadherent through intentional behavior. It was verified that two $(11.76 \%)$ study participants were not adhering to the prescribed medication due to both intentional and unintentional behavior.

\section{The degree of knowledge about the medication}

This study evaluated the degree of patient knowledge regarding the medication prescribed by the psychiatrist, comparing the last medical prescription available in the patient's records, with the medications referred to by the patient. The degree of knowledge was analyzed regarding the name, dose and frequency of the medications, as shown in Figure 1.

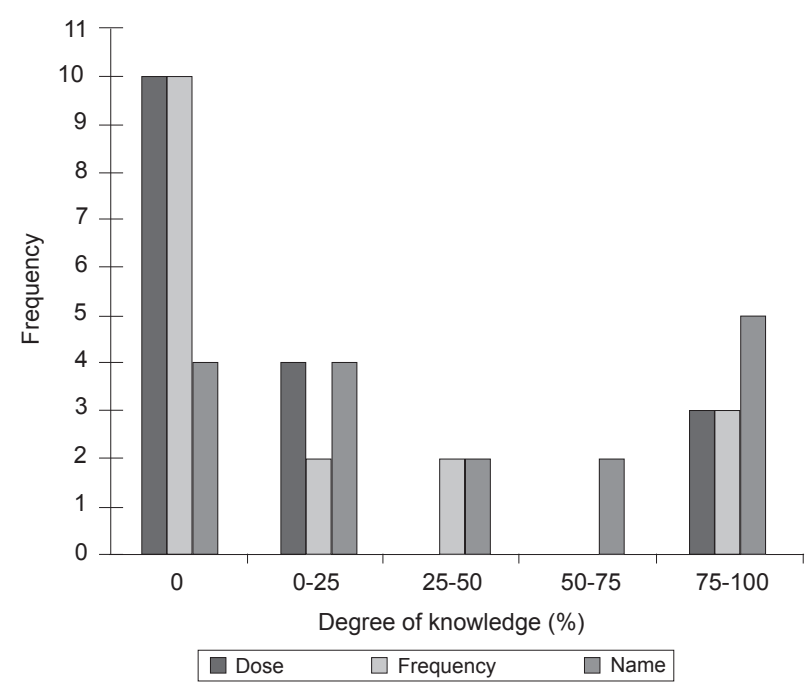

Figure 1 - Distribution of the study subjects according to the degree of knowledge of dosage, frequency and name of the medication

It was observed that the lowest degree of knowledge was related to the dose and frequency of medication administration. In both of the variables, the majority 
of interviewees (58.82\%) presented $0 \%$ knowledge. Regarding the dose, the responses considered correct were those that identified the quantity, in units of measurement (grams, milligrams and milliliters), to be administered at each time or within 24 hours, according to the medical prescription. Figure 1 shows that only five $(29.41 \%)$ patients were able to report more than $75 \%$ of the names of the medications in use. To evaluate their knowledge about the names of the medications the answer accepted as correct was one that identified the medication prescribed by either the generic name or by any commercial name.

\section{The difficulties related to the pharmacological therapy for elderly people with BAD}

From the content analysis of the interviews some categories emerged that described the difficulties in following the prescribed pharmacological treatment of elderly people with BAD, as described below.

\section{Needing to tolerate polypharmacotherapy}

This category describes the patient inserted on a trajectory of use of various types of medication in an attempt to stabilize the mood and control comorbidities. In addition to the psychotropic drugs prescribed to control the BAD, the elderly often need to continually use medication to control co-morbidities such as hypertension and diabetes, among others. In this context, the individual depreciates the fact of taking "too much medicine", as indicated by the reports below.

For high pressure I use Captopril, I have one that is for cholesterol that I cannot remember the name of, it is a small red pill... but I take Metformin because I have diabetes, I take Arzocon, also for diabetes, I take ASS ... I take the mental health medicine... Carbolitio, I take Chlorpromazine and Akineton... and I take Cloran in the morning. (S1)

I use Fluoxetine, Cortisone Acetate... I take vitamin B3, Calcium carbonate, Meprozol... it is a lot of medicine I take that for high pressure, Sodium Carbonate, Simvastatin one per night... Omeprazole ... Hydrochlorothiazide... I think it's too much medicine, I think to myself that it is too much medicine, so I don't see it. (S8)

It is a lot of medicine... Then I get confused... (S6)

It is worth noting that the need to use many drugs simultaneously is considered a "confusing" factor for the patient, impairing their independence to self-administer the prescribed medication.

Having limitations for the self-administration of the prescribed medication
It was identified that the difficulty of ingesting medication on time and in the correct dosage becomes pronounced in the elderly. This aspect is clearly identified in the statements of the interviewees, where forgetting is cited as an ordinary and relatively frequent event.

I would say that I forget about four times a month... (S7)

Forget, I forget a lot... About three times (per week)... (S16)

It was perceived that faced with the difficulties in administration of the medication, the elderly with BAD adopt various strategies to not forget when to do this, as revealed in the following reports.

When I go to lunch I put it here (points to table)... To not forget... And at two o'clock I take it, if I lie down a bit I set the alarm and to get up and take it. (S3)

I have a small bag of medicine. So I put everything there in sequence, then take the first, put it in the bag, the second, put it in the bag, otherwise I get confused, I do not know if I took it or if I did not take it, understand? (S4)

My medicine, it is all written down, the envelope of my medication was made with: the moon, the sun, so that I don't mix them, to not get confused with the medicine. The girl here who taught me, she makes the envelope. (S16)

When help is needed for the administration of their medication, there are elderly with BAD who have family support to make sure the therapy is followed correctly.

I do not take alone. My wife gives me (medication). I do not remember any. (S2)

They (family members) are quite on top of me... all the time asking if I am feeling better, taking the medicines correctly... they put the medicines near the TV so I will not forget to take. (S13)

However, not all the elderly people find the support they need for the pharmacological treatment to be adequately followed. The statements below highlight this issue.

They never put the pill in my hand, I can arrive at the hospital weak, never, never, never. (S3)

They do not help me, no my dear! There are things that I do not even like to talk about! So, we have to be very tolerant, right? (S8)

They do not help much... They are not accustomed to remembering their things much, so I take care of myself mostly. (S11)

\section{Needing to adhere, but wishing to not adhere to pharmacotherapy}

When living with a chronic disease that requires the prolonged use of a medication, the desire and hope to one day be able to terminate the pharmacological treatment was identified among the subjects. 
The other one (physician) said I'll have to take Carbolitio for my entire life, I said God willing I'll stop one day... I will ... but for now I cannot. (S5)

I say 'I do not think I need it anymore', you know? Because I take too much medicine... I feel like stopping the Haldol ... (S6)

The desire to quit using medication to control the disorder may be related to non-adherence. There were reports that highlighted how some patients experiment by interrupting the use of the medication.

I thought I was well, so I stopped taking the Carbolitio... I tried to stop, thinking that I was cured ... I think I stopped about three times because I thought I was good and I was reducing the medication on my own. (S4)

I stopped taking the medicine because I thought it was not doing anything... I already tried, you know? There was a time that I tried... to see if I could stay without taking the medicine, but I could not. (S9)

The statements reveal that attempting to stop the medication causes crises, the patients are afraid to initiate further attempt to discontinue the use of it.

I got a little angry that I had to take medicine, I said that I was not crazy, and then I said I did not need to take it at all... The days I stopped taking the medicine, I was screaming, I was desperate... Then I saw for myself that I could not go without the medicine. (S14)

I know it will give me problems if I don't take... I get much worse if I don't take... I'm worse without them, if I stop taking them, then I become crazy because of the illness. (S7)

I knew I was not going to improve if I did not take it, right? Then I said: "No... I cannot do this to myself..." so I started taking it again. (S12)

\section{Having collateral effects}

The prolonged use of medication causes, as a consequence, the emergence of collateral effects. The reports of the patients evidenced the presence of such effects, causing discomfort and restricting their quotidian activities. There were complaints of drowsiness, dizziness, stomach discomfort, dermatitis, tremors, weight gain and decreased libido.

I feel a great drowsiness, I sleep about 13 to 14 hours a day... and the sexual part too. I have been gradually reducing (the medication) and now it's really bad! This worries me more. (S7)

It bothers me... the tremors in the hands, because sometimes I'll go to read a paper and... it bothers me. (S5)

Getting fat... To get fat is not good, because we already have the problem that is chronic. (S1)

It gave me a skin allergy, made my skin all spotty, the Carbamazepine.

(S8)
I had difficulties because of the pain in my stomach... and I complain all the time. (S10)

It was verified, through the reports, that although the elderly patients recognized the necessity for the medication to control the BAD, the fear of its collateral effects is constant. The following statement expresses the desire of the elderly patients to use an alternative form of treatment (medicine) to psychotropic drugs.

It is ... it's bad for other things, but, what can you do? But at least the mind works, right?... It (the medicine) is very chemical then I talked to the Dr. I wanted to take another medicine that was less chemical. (S4)

\section{Questioning the need for the medication}

There were patients who did not have much information about the disorder so they questioned the necessity of prescribed pharmacological treatment. Their statements also revealed the desire to obtain information about the disorder and the medication in use.

I don't know why I have to be taking this (medication)... I did not want to accept at all that I had to be taking it... I had to leave a life that was normal. (S12)

I know that I have to take the medicine, but sometimes I don't know what for... I take the medicine to try to be well, right? But I do not know if I will be well with this medicine. (S15)

Until today I do not know what this disease is. However, I suffer more... Oh, I wish the person would tell me what this disease means. (S16)

It was verified among the study subjects that, when they perceive themselves using a lot of medication, presenting collateral effects from it, and not having immediate results, they begin to question the efficacy of the pharmacological treatment. Their statements also reveal that despite not perceiving improvement in the symptomology, "you must accept" the medication because "the doctor says so", expressing their total belief in the medical truth, becoming passive to the will of the physician.

If I take medicine for a headache, I feel better... with the Carbolithium I do not feel anything, if it improves, if it does not improve, I have to accept what the doctor says, right? But do I feel an improvement in my body? No, I feel nothing. (S5)

There are days when I say "I'm taking this medicine for nothing, just filling myself with medicine", it's not resolving anything. (S6)

\section{Discussion}

This study identified the degree of adherence to the pharmacological treatment, the level of knowledge 
and the difficulties of 17 elderly patients with BAD in relation to the pharmacotherapy prescribed. It was found that the majority $(76.47 \%)$ of the participants were female. Although, in the literature there is no significant difference in the prevalence of BAD between the genders, the higher number of women attended in the MHC could be due to the significantly lower tendency of men with BAD to seek medical attention when compared to women ${ }^{(19)}$.

The medication most commonly used by the study subjects for the control of psychiatric symptoms were mood stabilizers, followed by antipsychotics, benzodiazepines and antidepressants. These findings are corroborated by the literature which shows that currently BAD treatment in the elderly includes mood stabilizers (lithium, anticonvulsants) which, in some cases may be associated with antipsychotics, anxiolytics, antidepressants and electroconvulsive therapy $(6,20)$.

This study identified a high rate of non-adherence to the pharmacological treatment among the elderly patients with BAD. In this respect, the international literature shows that approximately $50 \%$ of bipolar patients interrupt the treatment at least once, while $30 \%$ of them do so at least twice ${ }^{(21)}$. It is noteworthy that non-adherence to medication significantly undermines the efficacy of it and is associated with poor prognosis, increased risk of relapse and suicide, and greater consumption of health system resources(22).

Low levels of patient knowledge, regarding the prescribed medication, were identified, and the knowledge deficit was higher in relation to the dose and frequency of administration of the medication. The lack of knowledge in this regard can cause both omissions of doses as well as extradoses. Thus, these elderly patients can be exposed to ineffective treatment through the use of pharmaceuticals below the therapeutic levels and the risk of toxicity due to the maintenance of medication above therapeutic doses, with such risks being exacerbated by the peculiarities of the metabolism of medication in the elderly(6).

This study found that only five patients were able to relate more than $75 \%$ of the names of the medications in use. Knowing the name of the medication is essential so that the patient knows how to differentiate it at the time of purchase and use, as well as being able to give information about them on the occasion of hospital admissions, examinations, adverse reactions and allergies, among others.

It is emphasized that knowledge regarding the name, dose and frequency of medication administration is of paramount importance for the patient to be able to avoid mistakes in their usage. The deficit of knowledge regarding this can indicate, among other aspects, a failure or deficiency in the process of patient education by health professionals.

The simultaneous use of multiple pharmaceuticals was one of the problems experienced in the following of the pharmacological therapy. According to the survey participants, the polypharmacotherapy may increase the difficulties for self-administration of the prescribed medications, raising the possibility of non-adherence. The use of many medications can also increase the likelihood of the occurrence of collateral effects.

The literature suggests that polypharmacy is a significant problem in old age that requires special attention from health professionals ${ }^{(3)}$. A study ${ }^{(23)}$ revealed that the majority of elderly people consume at least one medication and around one third of them consume five or more simultaneously, corroborating the findings of this study. The limitation of ingesting medication at the correct time and dosage becomes pronounced in the elderly, especially due to forgetting the time of administration. This difficulty in remembering the time of medication administration constitutes a risk of nonadherence due to non-intentional behavior, which was identified in $64.72 \%$ of the participants of this study. This aspect may be related, among other thing, to the polypharmacotherapy, to the disorder and to the age range studied, because elderly patients with BAD tend to present cognitive impairments hindering the recognition and retention of the medication administration schedules(23-24). For the elderly people with BAD who have limitations for the self-administration of medication it is crucial to involve the family in the provision of help. Family members of elderly outpatients with BAD are in a unique position to identify problems and to intervene collaborating in the treatment. To do so, it is necessary that they are assisted, prepared and supported by the health professionals(25).

It was found that the elderly patients with BAD had a desire to interrupt the pharmacotherapy, with some experimenting with discontinuing the use of medication to test the real necessity for it. In this respect, there are authors who mention that this kind of testing, that some more active patients, especially chronic patients, develop with their treatment, is justified by the intention to overcome the stigma of chronic disease as well as to mitigate certain interference in their quotidian caused by the rigid following of the medication prescriptions and their collateral effects ${ }^{(21,26)}$. 
It was perceived that when the attempt to interrupt the pharmacological treatment caused crises, the patients understood the need for the medication. It was noted that at this moment adherence is seen as the only path available to achieve emotional stability and, thus, the patient feels compelled to take the medication. The limitations and discomfort caused by the collateral effects of the medication are a constant in the quotidian of the elderly patients with BAD. The literature reveals that the collateral effects of the medication significantly impair the quality of life of the patients and may be the main obstacle for the adherence to the pharmacological

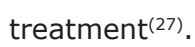

The lack of information regarding the disorder and lack of immediate results in the pharmacological treatment were related to doubts about the necessity and efficacy of the prescribed pharmacological treatment. These findings highlight the need for a greater investment in the education of the patients and family members in relation to the disorder and treatment.

In the following of the pharmacological therapy, the study participants faced a variety of difficulties which were closely interrelated and mutually reinforcing. The categories constructed in this study regarding the difficulties presented by the elderly patients with BAD may indicate problems that deserve to be investigated by the professionals who work in mental health.

\section{Final considerations}

This study verified the degree of adhesion, the level of knowledge and the difficulties associated with the pharmacological treatment in 17 elderly patients with BAD. A low level of adherence to the pharmacological therapy was identified in this population, which indicates a poor prognosis for the disorder in this clientele. It was found that there was a lack of knowledge, especially regarding the doses and frequency of the medication. This limitation indicates that these elderly patients may be exposed to important risks in the following of the pharmacological therapy, especially when using medication with a narrow therapeutic range. This finding also indicates the need for supervision of the elderly with BAD in the self-administration of the prescribed medication, the presence of a family member/caregiver being relevant. In this context, an important strategy to introduce the family member/caregiver into the care for the elderly in medication therapy consists of the organization, in the health institutions, of groups of family members for health education, coordinated by the professionals.
Educational actions involving elderly people with BAD are also very important, because the promotion of adherence to the treatment and a better understanding of this are aspects considered essential for safety in pharmacological therapy. Many difficulties in the following of the medication therapy were raised, which may contribute to the lack of medication adherence in the clientele of the study: the polypharmacotherapy, the collateral effects, the limitations for the selfadministration of the prescribed medication, the lack of information about the disorder and treatment, the belief that the medication is ineffective, and the desire to interrupt the pharmacological treatment. Such problems deserve to be investigated by the professionals in the clinical practice so that interventions can be established that can minimize the consequences of the treatment.

By caring for elderly patients with BAD, it is essential to know the limitations, motivations and barriers that they may face in the following of the pharmacological therapy. Merely having this knowledge, the health professional may propose actions that impact on the reality of the client. The results of this study also highlight the need to implement strategies that motivate the patients to adhere to the pharmacological therapy, assuming greater responsibility and active participation in the treatment instituted.

\section{References}

1. Instituto Brasileiro de Geografia e Estatística (IBGE) - Indicadores Sociodemográficos e de Saúde no Brasil 2009. Tabulação avançada. [acesso 19 junho 2010]. Disponível em: http://www.ibge.gov.br/ home/estatistica/populacao/indic_sociosaude/2009/ indicsaude.pdfhttp

2. Fialová D, Onder G. Medication errors in elderly people: contributing factors and future perspectives. $\mathrm{Br}$ J Clin Pharmacol. 2009; 67(6):641-5.

3. Rossi MI, Young A, Rodriguez KL, Appelt CJ, Perera $S$, Hajjar ER, et al. Polypharmacy and health beliefs in older outpatients. Am J Geriatr Pharmacother. 2007; 5(4):317-23.

4. Depp CA, Jeste DV. Bipolar disorder in older adults: a critical review. Bipolar Disord. 2004; 6(5):343-67.

5. Zung SP. Estudo comparativo com ressonância magnética em idosos com transtorno afetivo bipolar usuários ou não de lítio [tese de doutorado]. São Paulo (SP): Faculdade de Medicina da Universidade de São Paulo; 2007. 175 p. 
6. Aziz R, Lorberg B, Tampi RP. Treatments for latelife bipolar disorder. Am J Geriatr Pharmacoter. 2006; 4(4):347-64.

7. Miasso AI, Cassiani SHB, Pedrão LJ. Transtorno afetivo bipolar e terapêutica medicamentosa: identificando barreiras. Rev. Latino-Am. Enfermagem. 2008; 16(4):739-45.

8. Miasso AI, Monsteschi M, Giacchero KG. Transtorno afetivo bipolar: adesão ao medicamento e satisfação com o tratamento e orientações da equipe de saúde de um núcleo de saúde mental. Rev. Latino-Am. Enfermagem. 2009; 17 (4):548-56.

9. Sajatovic M, Madhusoodanan S, Coconcea N. Managing bipolar disorder in the elderly: defining the role of the newer agents. Drugs Aging. 2005; 22(1):39-54.

10. Folstein F, Folstein SE, McHugh PR. "Mini-mental state". A pratical method for grading the cognitive state of patients for the clinician. J Psychiatr Res. 1975; 12:189-98.

11. Lourenco RA; Veras RP. Mini-Exame do Estado Mental: características psicométricas em idosos ambulatoriais. Rev Saúde Pública. 2006; 40(4):712-9.

12. Morisky DE, Green LW, Levine DM. Concurrent and predictive validity of a self-reported measure of medication adherence. Med Care. 1986; 24:67-74.

13. Teixeira ACA. Adesão ao tratamento farmacológico da hipertensão arterial e seus determinantes em pacientes de ambulatório [dissertação de mestrado]. Fortaleza (CE): Faculdade de Medicina da Universidade Federal do Ceará; 1998. 102 p.

14. Garcia RAC. Os fatores de aderência ao tratamento farmacológico de hiperlipidemias em pacientes atendidos pela Secretaria Municipal de Saúde de Ribeirão Preto [dissertação de mestrado]. Ribeirão Preto (SP): Faculdade de Medicina de Ribeirão Preto/USP; 2003.104p.

15. Strelec MAAM, Pierin AMG, Mion Júnior D. A influencia do conhecimento sobre a doença e a atitude frente à tomada de remédios no controle da hipertensão arterial. Arq Bras Cardiol. 2003; 81:349-54.

16. Stape DDB. O conhecimento do paciente com alta hospitalar sobre a continuidade do seu tratamento [dissertação de mestrado]. São Paulo (SP): Escola de Enfermagem/USP; 1979. 118 p.

17. Miasso AI. Terapêutica medicamentosa: orientação e conhecimento do paciente na alta e pós-alta hospitalar [dissertação de mestrado]. Ribeirão Preto (SP): Escola de Enfermagem de Ribeirão Preto/USP; 2002. 118 p.

18. Minayo MCS. O desafio do conhecimento: pesquisa qualitativa em saúde. 6a ed. São Paulo: Hucitec; Rio de Janeiro: Abrasco; 1999.
19. Dias RS, Kerr-Corrêa F, Torresan RC, Santos CHR. Transtorno bipolar do humor e gênero. Rev Psiquiatr Clín. 2006; 33(2):80-91.

20. Diana R, Sanderson MD. Practical Geriatrics: Use of Mood Stabilizers by Hospitalized Geriatric Patients With Bipolar Disorder. Psychiatr Serv. 1998; 49:1145-7.

21. Lingam R, Scott J. Treatment Non-adherence in Affective Disorders. Acta Psychiatr Scand. 2002; 105:164-72.

22. Pompili M, Serafini G, Del Casale A, Rigucci S, Innamorati $M$, Girardi $P$, et al. Improving adherence in mood disorders: the struggle against relapse, recurrence and suicide risk. Expert Rev Neurother. 2009; 9(7):9851004.

23. Rozenfeld S. Prevalência, fatores associados e mau uso de medicamentos entre os idosos: uma revisão. Cad Saúde Pública. 2003; 19(3):717-24.

24. Schouws SN, Comijs HC, Stek ML, Dekker J, Oostervink F, Naarding $P$, et al. Cognitive impairment in early and late bipolar disorder. Am J Geriatr Psychiatry. 2009; 17(6):508-15.

25. Barroso SM, Bandeira M, Nascimento E. Sobrecarga de familiares de pacientes psiquiátricos atendidos na rede pública. Rev Psiquiatr Clín. 2007; 34(6):270-7.

26. Sajatovic M, Bauer MS, Kilbourne AM, Vertress JE, Williford W. Self-reported medication treatment adherence among veterans with bipolar disorder. Psychiatr Serv. 2006; 57:56-62.

27. Sachs GS. Unmet clinical needs in bipolar disorder. J Clin Psychopharmacol. 2003; 3 Suppl 1:2-8.
Received: Dec. $22^{\text {nd }} 2009$ Accepted: Nov. 22 2010 